\title{
Vapor intrusion in soils with multimodal pore-size distribution
}

\author{
Alfaro Soto Miguel $^{1 a}$ and Hung Kiang Chang ${ }^{2}$ \\ ${ }^{1,2}$ UNESP, Universidade Estadual Paulista, Departamento de Geologia, Rio Claro-SP, Brazil
}

\begin{abstract}
The Johnson and Ettinger [1] model and its extensions are at this time the most widely used algorithms for estimating subsurface vapor intrusion into buildings (API [2]). The functions which describe capillary pressure curves are utilized in quantitative analyses, although these are applicable for porous media with a unimodal or lognormal pore-size distribution. However, unaltered soils may have a heterogeneous pore distribution and consequently a multimodal pore-size distribution [3], which may be the result of specific granulometry or the formation of secondary porosity related to genetic processes. The present paper was designed to present the application of the Vapor Intrusion Model (SVI_Model) to unsaturated soils with multimodal pore-size distribution. Simulations with data from the literature show that the use of a multimodal model in soils with such pore distribution characteristics could provide more reliable results for indoor air concentration, rather than conventional models.
\end{abstract}

\section{Introduction}

The contamination of subsurface soils and underground waters can contain chemicals vapors and migrate from the subsurface to nearby basements, buildings, and other enclosed spaces and move by diffusion through the soil and any covering material (concrete, floors, geomembranes, etc.), or by advection along preferential paths (cracks, fractures, ducts, etc.).

According to USEPA [4], the model of Johnson and Ettinger [1] is designed to provide a solution for either a state-state to vapor transport (finite or non-dinimishing source) and as quasy-steady-state (finite or dinimishing source). The input of the model include chemical properties of the contaminant, properties of the saturated and unsaturated soil, and the structural characteristics or properties of a building.

In relation to the properties of soils, the model of Johnson and Ettinger [1] considers, among other factors, the functions which describe the capillary pressure curves in quantitative analyses. However, these equations were designed for porous media with a unimodal or lognormal pore-size distribution. Unaltered soils, however, may have heterogeneous systems of pores, and hence, multimodal pore-size distributions [3]. According to Mallants [5], may be the result of aggregation and/or biological processes, but have also been observed in morainic and solifluction soils

This means that predictions the transport of contaminant vapors emanating from subsurface soils into indoor spaces located above the source of contamination on present-day may be different in situations in which soil porosity involves a system of multimodal pores.

\footnotetext{
${ }^{\mathrm{a}}$ Corresponding author: alfaro@rc.unesp.br
}

The present paper was thus designed to furnish suggestions for the determination of concentrations arising from vapor intrusion into closed environments, including transport by diffusion through concrete from contaminated soils with a multimodal pore distribution.

\section{Experimental and analytic methods}

\subsection{Contaminant vapors from subsurface soils into indoor spaces (Johnson and Ettinger [1])}

According to Johnson and Ettinger [1] and USEPA [4], the concentration of contaminating vapour in closed environments can be calculated using the following expression:

$$
C_{\text {building }}=\alpha \cdot C_{\text {source }}
$$

Where $C_{\text {buiding }}\left(\mu \mathrm{g} . \mathrm{m}^{-3}\right)$ represents the indoor air concentration of a specific chemical under steady-state condition, $C_{\text {source }}\left(\mu \mathrm{g} . \mathrm{m}^{-3}\right)$ concentration at the source and $\alpha$ represent the steady state attenuation coefficient.

$$
\begin{aligned}
& \alpha=\frac{[(a) x \exp (b)]}{\left[\exp (b)+(a)+(c)\left[\exp (b)^{`}-1\right]\right]} \\
& a=\frac{D_{T}^{\text {eff }} A_{B}}{Q_{\text {bulding }} L_{T}} \\
& b=\frac{Q_{\text {soil }} L_{\text {crack }}}{D^{\text {crack }} A_{\text {crack }}} \\
& c=\frac{D_{T}^{\text {eff }} A_{B}}{Q_{\text {soil }} L_{T}}
\end{aligned}
$$


Where $A_{B}$ represents the area of the enclosed space below grade $\left(\mathrm{m}^{2}\right), L_{T}(\mathrm{~m})$ souce buiding separation, $L_{\text {crack }}$ (m) enclosed space foundation or slab thickness, $A_{\text {crack }}$ $\left(\mathrm{m}^{2}\right)$ area of total cracks, $Q_{\text {bulding }}\left(\mathrm{m}^{3} \cdot \mathrm{s}^{-1}\right)$ building ventilation rate, $Q_{\text {soil }}\left(\mathrm{m}^{3} . \mathrm{s}^{-1}\right)$ the volumetric flow rate of soil gas entering the building and $D_{\text {crack }}\left(\mathrm{m}^{2} . \mathrm{s}^{-1}\right)$ the effective diffusion coefficient through the cracks. On the other hand, $D_{T}^{\text {eff }}\left(\mathrm{m}^{2} . \mathrm{s}^{-1}\right)$ represents the total overall effective diffusion coefficient. According to USEPA [4] the $D_{i}^{e f f}$ of the layer of soil in contact with the floor can be assumed to be equivalent to the coefficient of effective diffusion through the cracks $\left(D_{\text {crack }}\right)$. The coefficient of effective diffusion in the unsaturated zone can be expressed by:

$$
\begin{gathered}
D_{i}^{e f f}=D_{a}\left(\theta_{a, i}^{3.33} / n_{i}^{2}\right)+\left(D_{w} / H_{T S}^{\prime}\right)\left(\theta_{w, i}^{3.33} / n_{i}^{2}\right) \\
\theta_{a, i}=n_{i}-\theta_{w, i} \\
\theta_{w, i}=\theta_{r}+\frac{\theta_{s}-\theta_{r}}{\left[1+(\alpha h)^{N}\right]^{M}}
\end{gathered}
$$

Where $D_{a} \quad\left(\mathrm{~m}^{2} \cdot \mathrm{s}^{-1}\right)$ and $D_{w} \quad\left(\mathrm{~m}^{2} \cdot \mathrm{s}^{-1}\right)$ represent diffusivity in air and water, respectively; $n_{\mathrm{i}}(\mathrm{m} 3 / \mathrm{m} 3)$ represents the total porosity in the layer $i, H_{T S}^{\prime}(-)$ Henry's law constant at the system temperature, $\theta_{a, i}$ $\left(\mathrm{m}^{3} / \mathrm{m}^{3}\right)$ and $\theta_{w, i}\left(\mathrm{~m}^{3} / \mathrm{m}^{3}\right)$ the porosity of the soil filled with air and water respectively in the layer $i, \theta_{s}\left(\mathrm{~m}^{3} / \mathrm{m}^{3}\right)$ and $\theta_{r}\left(\mathrm{~m}^{3} / \mathrm{m}^{3}\right)$, respectively, the saturated and residual water content, $\alpha\left(\mathrm{m}^{-1}\right), N$ and $M$ van Genuchten's [6] parameters, and $h(\mathrm{~m})$ pressure head.

On the other hand, the buiding ventilation rate $\left(Q_{\text {bulding }}\right)$ is obtained from the following:

$$
Q_{\text {buiding }}=\left(L_{B} \cdot W_{B} \cdot H_{B} \cdot E R\right) / 3600 s / h
$$

Where $L_{B}(\mathrm{~m}), W_{B}(\mathrm{~m})$ and $H_{B}(\mathrm{~m})$ represent the length, width and height of of the building and $E R\left(\mathrm{~h}^{-1}\right)$ the air exchange rate.

The volumetric flow rate of soil gas entering the buiding $Q_{\text {soil }}\left(\mathrm{m}^{3} \cdot \mathrm{s}^{-1}\right)$ is given by:

$$
Q_{\text {soil }}=\frac{2 \pi \cdot \Delta P \cdot k_{v} \cdot X_{\text {crack }}}{\mu \cdot \ln \left(2 Z_{\text {crack }} / r_{\text {crack }}\right)}
$$

Where $\triangle P(\mathrm{~Pa})$ represents the pressure between de soil surface and the enclosed space, and $k_{v}\left(\mathrm{~m}^{2}\right)$ soil vapor permeability, $X_{\text {crack }}(\mathrm{m})$ floor wall seam perimeter, $\mu$ the viscosity of the air $\left(1.78 \times 10^{-5} \mathrm{~kg} \cdot \mathrm{m}^{-1} . \mathrm{s}^{-1}\right), Z_{\text {crack }}(\mathrm{m})$ crack depth below grade, and $r_{\text {crack }}(\mathrm{m})$ equivalent crack radius. Moreover, the soil vapor permeability is given by:

$$
\begin{gathered}
k_{v}=k_{i} \cdot k_{r g} \\
k_{i}=\frac{K_{s} \mu_{w}}{\rho_{w} g} \\
k_{r g}=\left(1-S_{t e}\right)^{1 / 2}\left(1-S_{t e}^{1 / M}\right)^{2 M}
\end{gathered}
$$

Where $k_{i} \quad\left(\mathrm{~m}^{2}\right)$ represents the soil intrinsic permeabilty and $k_{r g}(-)$ the relative air permeability $(0 \leq$ $\left.\mathrm{k}_{\mathrm{rg}} \leq 1\right)$. Moreover, $K_{s}\left(\mathrm{~m} \cdot \mathrm{s}^{-1}\right)$ is the soil saturated hydraulic conductivity, $\mu_{w}\left(\mathrm{~g} \cdot \mathrm{m}^{-1} \cdot \mathrm{s}^{-1}\right)$ the dynamic viscosity of water, $\rho_{w}\left(\mathrm{~kg} \cdot \mathrm{m}^{-3}\right)$ density of water and $g$ $\left(\mathrm{m} . \mathrm{s}^{-2}\right)$ the acceleration due to gravity, and $S_{t e}(-)$ the effective total fluid saturation, represented by:

$$
S_{t e}=\left(\theta_{w}-\theta_{r}\right) /\left(n-\theta_{r}\right)
$$

Based on the model of Johnson and Ettinger [1] and USEPA [4], Putzman [7] incorporates diffusion through concrete in the model formulation, allowing for the possibility to calculate the indoor air concentration by advective and diffusive transport through cracks and also considering the volatile contaminants diffusion through concrete. Thus $\alpha$ is represented by:

$$
\begin{aligned}
& \alpha=\frac{[(a) x \exp (d)]}{[\exp (d)+(a)+(c)[\exp (d)-1]]} \\
& d=\frac{Q_{\text {soil }} L_{\text {crack }}}{\left(D^{\text {crack }} A_{\text {crack }}\right)+\left(D_{\text {conc }}^{\text {eff }} A_{\text {conc }}\right)}
\end{aligned}
$$

Where $D_{\text {conc }}^{\text {eff }}\left(\mathrm{m}^{2} . \mathrm{s}^{-1}\right)$ represents the effective diffusion coefficient through concrete and other isolation layer types and $A_{\text {conc }}\left(\mathrm{m}^{2}\right)$ the area of enclosed space below grade without considering cracks area.

\subsection{Contaminant vapor from subsurface soils with multimodal pore-size distribution into indoor spaces}

As mentioned above, the proposals of Johnson and Ettinger [1] and USEPA [4] are based partially on soil parameters, including the concentration of vapor contaminants into indoor spaces. This can be seen from Eq.3 and Eq.7, where $D_{i}^{\text {eff }}$ and $Q_{\text {soil }}$, respectively depend indirectly on the capillary pressure curve of the soil (Eq.5). However, some porous media have systems of pores that cannot be represented by sigmoidal curves of capillary pressure because they have secondary or multiple systems of pores.

For this paper, an equation similar to that of van Genuchten [6] was used (Eq. 5), one which is capable of describing the capillary pressure of a heterogeneous system of pores. This model was developed by Durner [3]:

$$
S_{t e}=\sum_{i=1}^{k} w_{i}\left(1+\left(\alpha_{i} h\right)^{N_{i}}\right)^{-M_{i}}
$$

Where $k$ represents the number of subsystems making up the total distribution of pores and $w_{i}$ the weighting factors of the subcurves, varying from 0 to 1 . Similar to the unimodal model, the parameters of the subcurves $\alpha_{i}$ $\left[\mathrm{L}^{-1}\right], N_{i}[-]$ and $M_{i}[-]$ correspond to the parameters of adjustment. In this way, the coefficient of effective 
diffusion in the unsaturated zone can consider the distribution of multimodal pores; it is expressed as:

$$
\begin{gathered}
D_{i}^{e f f}=D_{a}\left(\theta_{m a, i}^{3.33} / n_{i}^{2}\right)+\left(D_{w} / H_{T S}^{\prime}\right)\left(\theta_{m w, i}^{3.33} / n_{i}^{2}\right) \\
\theta_{m a, i}=n_{i}-\theta_{m w, i} \\
\theta_{m w, i}=\theta_{r}+\left(\theta_{s}-\theta_{r}\right) \sum_{i=1}^{k} w_{i}\left(1+\left(\alpha_{i} h\right)^{N_{i}}\right)^{-M_{i}}
\end{gathered}
$$

Where $\theta_{m a, i}\left(\mathrm{~m}^{3} / \mathrm{m}^{3}\right)$ and $\theta_{m w, i}\left(\mathrm{~m}^{3} / \mathrm{m}^{3}\right)$ represent the soil air-filled and soil water-filled, respectively, in the layer $i$ of a soil with a multimodal distribution of pores. Moreover, volumetric flow rate of soil gas in such a soil with a multimodal distribution of pores can be represented by the following:

$$
Q_{\text {soil }}=\frac{2 \pi \cdot \Delta P \cdot k_{\text {vm }} \cdot X_{\text {crack }}}{\mu \cdot \ln \left(2 Z_{\text {crack }} / r_{\text {crack }}\right)}
$$

Where $k_{v m}\left(\mathrm{~m}^{2}\right)$ represents the soil vapor permeability of the soil with multimodal pore-size distribution:

$$
\begin{gathered}
k_{v m}=k_{i} \cdot k_{r g m} \\
k_{r g m}\left(S_{t e}\right)=\left(\sum_{i=1}^{k} w_{i}\left(1-S_{t e}\right)\right)^{0,5} \frac{\sum_{i=1}^{k} w_{i}^{2} \alpha_{i}^{2}\left(1-S_{t e}^{1 / M_{i}}\right)^{2 M_{i}}}{\left(\sum_{i=1}^{k} w_{i} \alpha_{i}\right)^{2}}
\end{gathered}
$$

The multimodal relative air permeability $\left(k_{r g m}\right)$ has been determined here on the basis of the expression of the unsaturated hydraulic conductivity function of Mualemvan Genuchten, considering that the effective total saturations is equal to $100 \%$ :

$$
S_{t e g}=1-S_{t e}
$$

Where $S_{\text {teg }}$ is the effective saturation of air in unsaturated soil.

\section{Results and discussion}

\subsection{Parameters of soils and capillary pressure curves}

Soil A is a sandy loam from the experimental field in Bekkevort, in Belgium [4], and soil B is a silty clay from the city of Londrina, in the state of Paraná in Brazil [8]; these examples were chosen because of the multimodal nature of the distribution of pores.

Figure 1 shows the results for the capillary pressure curve adjusted for non linear regression (LevenbergMarquardt) using the model defined by Eq.5 and 16 for unimodal and multimodal (bimodal and trimodal) poresize distribution, respectively.

Figure 1 shows the peculiar shape of the curve from the experimental data and the inadequacy of the adjustment using the unimodal model (Eq.5). On the other hand, Table 1 shows that the highest coefficients $\mathrm{R}^{2}$ result from the trimodal adjustment for soil $\mathrm{A}$, followed by the bimodal one for soil $\mathrm{B}$.

\subsection{Indoor air concentration of the contaminant ( $\mathrm{C}_{\text {building }}$ )}

A hypothetical situation of a homogeneous layer of soil with a source of contamination at a depth of $2 \mathrm{~m}$ was considered. The indoor air concentration of the contaminants $\left(C_{\text {buiding }}\right)$ was obtained by considering the coefficient of attenuation of Eq.12, i.e., considering advection via cracks and diffusion through concrete. It should be mentioned that this coefficient was obtained by the traditional unimodal method, but considering the multimodal nature of the pore-size distribution (Eq.14 to $20)$, as well as for different values of pressure head $(0.05$, $0.1,0.5,1$ and $10 \mathrm{~m}$ ), i.e., with decreasing values of volumetric water content from an initial level close to saturation.

The contaminant is a LNAPL (Ligth Non-aqueous Phase Liquid) composed of benzene, xylene and toluene, with concentrations of 1500, 7596 and $9300 \mu \mathrm{g} . \mathrm{m}^{-3}$, respectively. Certain chemical properties such as the enthalpy of vaporization at the normal boiling point, critical temperature, normal boiling point, Henry's law constant at the reference temperature, Henry's law constant at the system temperature, diffusivity in air and water, as well as the effective diffusion coefficient through concrete were taken from USEPA [4].

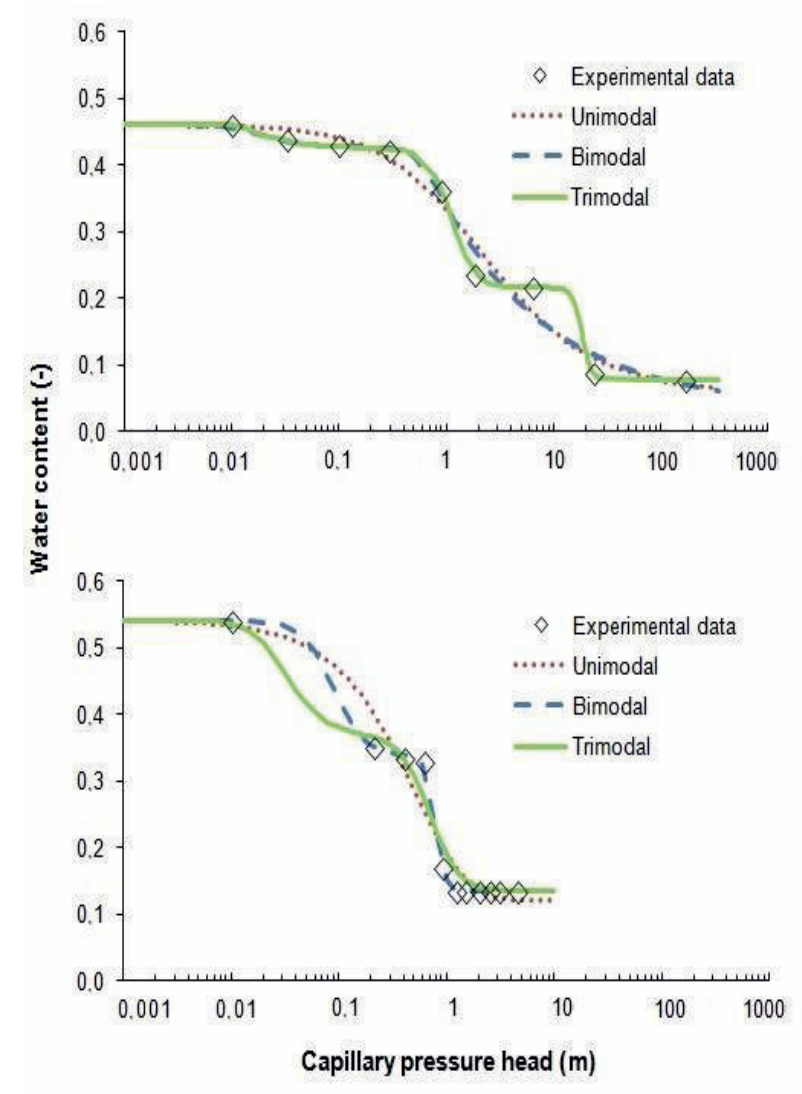

Figure 1. Experimental data (volumetric humidity x capillary pressure) and adjustment curves considering uni, bi and trimodal pore-size distributions for soils $\mathrm{A}$ and $\mathrm{B}$. 
The adjustment parameters of the capillary pressure curves in Table 1 were used for the characteristics of the porous medium. Moreover, the table includes the values of saturated hydraulic conductivity.

The dimensions of and information about the buildings were based on a hypothetical situation: length, width, and height of 10,10 and $3 \mathrm{~m}$, respectively; an air exchange rate of $0,5 \mathrm{~h}^{-1}$; a soil-building pressure differential of $5 \mathrm{~Pa}$; a depth below grade to bottom of enclosed floor space of $0,20 \mathrm{~m}$ and a ratio of area of cracks to total area of $0,01 \%$.

Figure 2 compares the results of concentration obtained by the traditional methods for the chemical considered (Benzene, Xylene and Toluene) obtained for soils A and B.

Table 1. Adjustment parameters estimated for capillary pressure curves

\begin{tabular}{|c|c|c|}
\hline \multirow[b]{2}{*}{ Parameter } & \multicolumn{2}{|c|}{ Soils } \\
\hline & $\mathrm{A}$ & B \\
\hline \multicolumn{3}{|c|}{ Unimodal } \\
\hline$\theta_{\mathrm{r}}$ & 0.0580 & 0.1214 \\
\hline$\alpha_{1}\left(m^{-1}\right)$ & 0.6900 & 0.1900 \\
\hline $\mathrm{N}_{1}$ & 0.9842 & 0.9950 \\
\hline$M_{1}$ & 0.717 & 10.076 \\
\hline $\mathrm{R}^{2}$ & 0.971 & 0.9350 \\
\hline \multicolumn{3}{|c|}{ Bimodal } \\
\hline$\theta_{\mathrm{r}}$ & 0.0370 & 0.1347 \\
\hline$w_{1}$ & 0.9197 & 0.4989 \\
\hline$w_{2}$ & 0.0803 & 0.5011 \\
\hline$\alpha_{1}\left(m^{-1}\right)$ & 8.1000 & 1.2800 \\
\hline$\alpha_{2}\left(m^{-1}\right)$ & 68.400 & 11.330 \\
\hline $\mathrm{N}_{1}$ & 5.7555 & 9.8956 \\
\hline $\mathrm{N}_{2}$ & 2.8515 & 2.9527 \\
\hline$M_{1}$ & 0.0736 & 1.0000 \\
\hline $\mathrm{M}_{2}$ & 0.5640 & 0.9723 \\
\hline $\mathrm{R}^{2}$ & 0.9780 & 0.9990 \\
\hline \multicolumn{3}{|c|}{ Trimodal } \\
\hline$\theta_{\mathrm{r}}$ & 0,0780 & 0,1355 \\
\hline$w_{1}$ & 0.3608 & 0,5050 \\
\hline$w_{2}$ & 0.5432 & 0.0646 \\
\hline$w_{3}$ & 0.0959 & 0.4304 \\
\hline$\alpha_{1}\left(m^{-1}\right)$ & 0.5400 & 1.4300 \\
\hline$\alpha_{2}\left(m^{-1}\right)$ & 0.8900 & 1.5200 \\
\hline$\alpha_{3}\left(m^{-1}\right)$ & 82.010 & 37.140 \\
\hline $\mathrm{N}_{1}$ & 9.9996 & 3,3733 \\
\hline $\mathrm{N}_{2}$ & 4.0876 & 3.1467 \\
\hline $\mathrm{N}_{3}$ & 9.9994 & 3.0302 \\
\hline$M_{1}$ & 1.0000 & 1.0000 \\
\hline$M_{2}$ & 1.0000 & 0.9203 \\
\hline$M_{3}$ & 0.1075 & 0.6263 \\
\hline $\mathrm{R}^{2}$ & 1.0000 & 0,9680 \\
\hline $\mathrm{K}_{\mathrm{s}}\left(\mathrm{m} \cdot \mathrm{h}^{-1}\right)$ & 0.0420 & 0.0012 \\
\hline
\end{tabular}

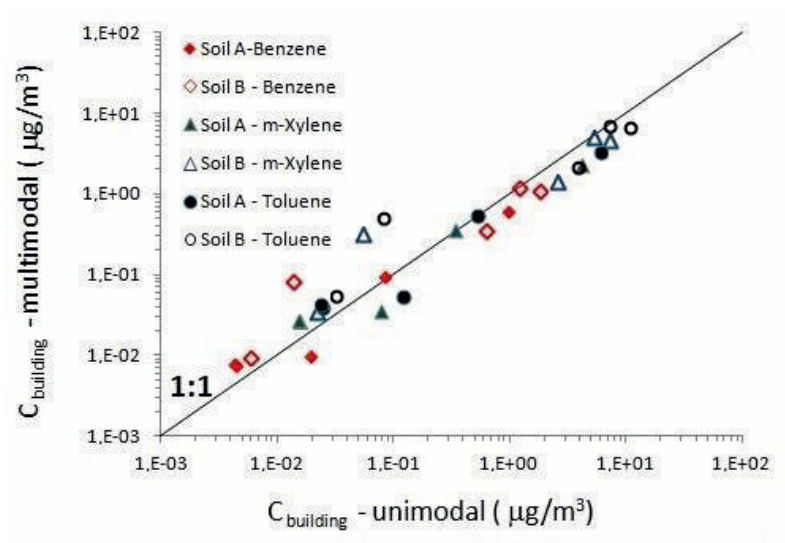

Figure 2. Comparison of $\mathrm{C}_{\text {bulding }}$ determined for soils $\mathrm{A}$ and $\mathrm{B}$ and the different chemicals for unimodal and multimodal poresize distribution.

This figures makes it clear that for either kind of soil (sandy loam or silty clay) and any chemical considered, the results for their concentration $\left(C_{\text {buiding }}\right)$ calculated on the basis of the traditional unimodal method of calculation, generally are relatively higher (when values greater than $0.2 \mu \mathrm{g} / \mathrm{m}^{3}$ ) than those which consider the multimodal pore-size distribution in the soil.

Figure 3 compares the results of the concentration found for the two soils (the sandy loam of A and the silty clay of B) determined by the unimodal and multimodal methods for the different chemicals. These results lead to the inference that the highest final concentrations $C_{\text {buiding }}$ come from the fine-textured soil $\mathrm{B}$, whatever the chemical considered and method of calculation utilized. This may be due to the elevated total porosity of the soil $\mathrm{B}(0.54)$ in relation to that of soil A $(0.46)$, as well as the fact that for the same capillary pressure head, the level of volumetric water content of soil A was greater than that of soil B, which reduced the flow of the contaminant in the form of vapour.

Figures 4 and 5 compares the average values of $C_{\text {buiding }}$ obtained for the different capillary pressures $(0.05$, $0.1,0.5,1$ and $10 \mathrm{~m}$ ) when calculated using the two methods (unimodal and multimodal) for each chemical for the two soils (A and B; Figuras 4 and 5, respectively). As can be seen, whatever the type of soil, the traditional unimodal model overestimates the values for soils with a multimodal pore-size distribution. 


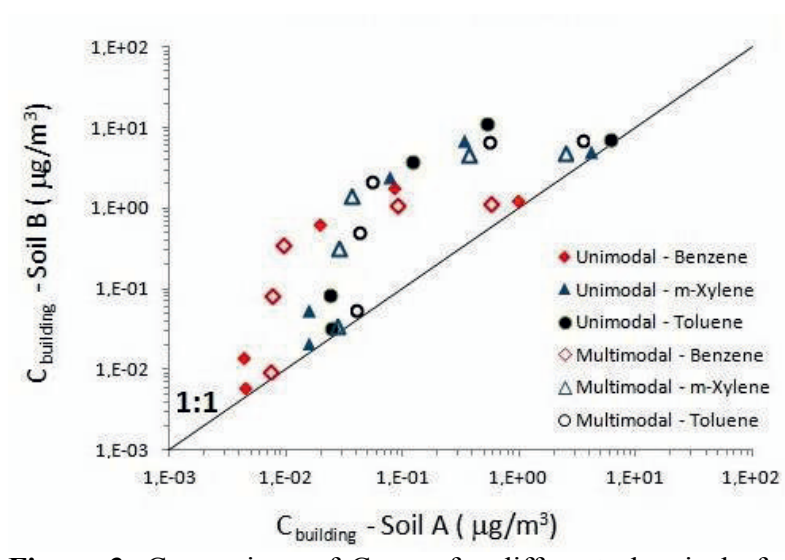

Figure 3. Comparison of $C_{\text {bulding }}$ for different chemicals from soils $\mathrm{A}$ and $\mathrm{B}$ when calculated by the traditional method and that for soils with multimodal pore-size distribution.

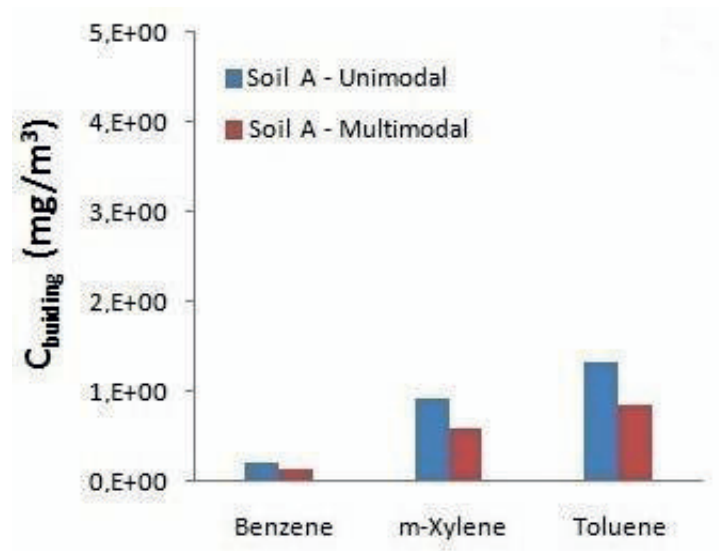

Figure 4. Comparison of $\mathrm{C}_{\text {bulding }}$ for the different chemicals for the soil A when calculated using the traditional method and that for a multimodal pore distribution

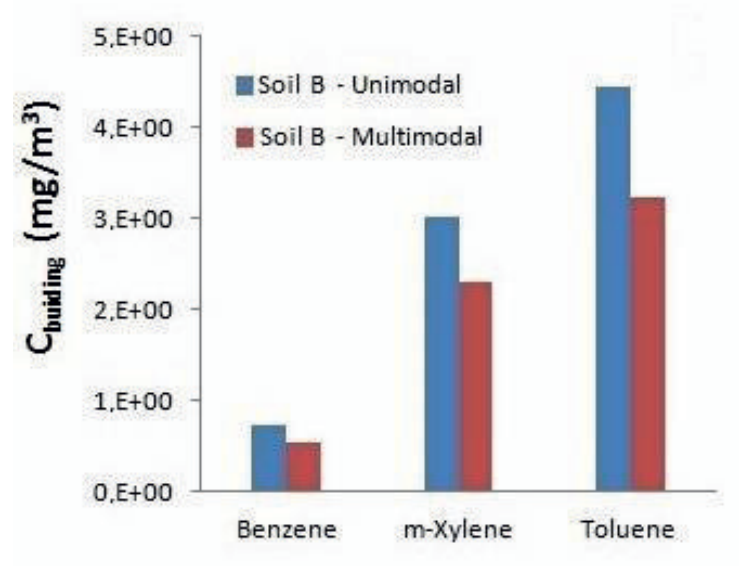

Figure 5. Comparison of $\mathrm{C}_{\text {bulding }}$ for the different chemicals for the soil $\mathrm{B}$ when calculated using the traditional method and that for a multimodal pore distribution

\section{Conclusions}

The results obtained here make it possible to infer that the use of traditional models for the determination of the indoor air concentration of the contaminants can lead to errors of overestimation in the neighborhood of 200 to $600 \%$ as a function of the type of soil when these have a multimodal distribution of pores, such as those found in many Brazilian states.

\section{References}

1. Johnson, P.C. and Ettinger, R.A. Heuristic model for predicting the intrusion rate of contaminant vapors into buildings, Environ. Sci. Technol., 25, 14451452. (1991)

2. API - American Petroleum Institute. Light NonAqueous Phase Liquid Distribution and Recovery Model (LDRM), API Publication 4760, (2007).

3. Durner W. Hydraulic conductivity estimation for soils with heterogeneous pore structure. Water Resources Research 30, 211-223.(1994)

4. USEPA, User's guide for evaluating subsurface vapor intrusion into buildings. In: Enviromental Quality Management I., ed. Washington, DC. (2004)

5. Mallants, D.; Tseng, P. H.; Toride, N.; Timmerman, A.; Feyen J. Evaluation of multimodal hydraulic functions in characterizing a heterogeneous field soil. Journal of hydrology, 95, 172-199. (1997)

6. van Genuchten M. Th. A closed-form equation for predicting the hydraulic conductivity of unsaturated soils. Soil. Sci. Soc. Am. J, 44: 892-898. (1980)

7. Putzmann T, de Biase C, Loechel S,, Bittens M., Weiss H. Soil Vapour Intrusion - A new model for the determination of indoor air concentrations. II Congresso Internacional de Meio Ambiente Subterrâneo. 04 a 06/2011, São Paulo - SP, Brazil.

8. Miguel, M. G.; Teixeira, R. S.; Padilha, A. C. C. Curvas características de sucção de solo laterítico da região de Londrina-PR. Revista de Ciência e Tecnologia, 12 (24), 63-74.(2006). 